\title{
Contribution of ship emissions to the concentration and deposition of air pollutants in Europe
}

\section{S. Aksoyoglu et al.}

Correspondence to: Sebnem Aksoyoglu (sebnem.aksoyoglu@psi.ch)

The copyright of individual parts of the supplement might differ from the CC-BY 3.0 licence. 
a)

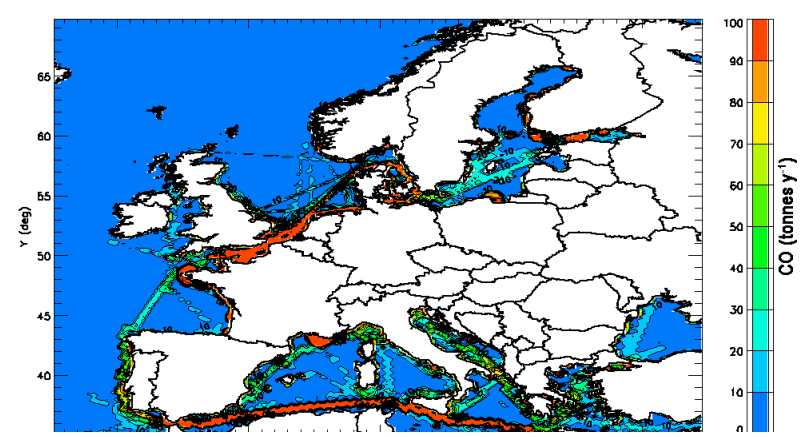

c)

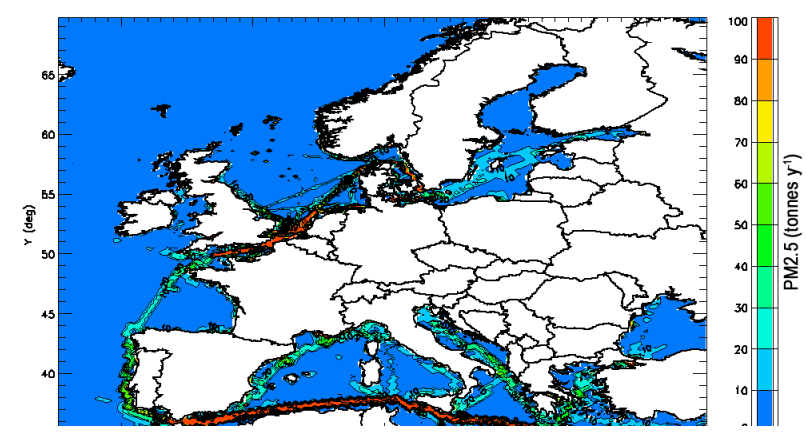

b)

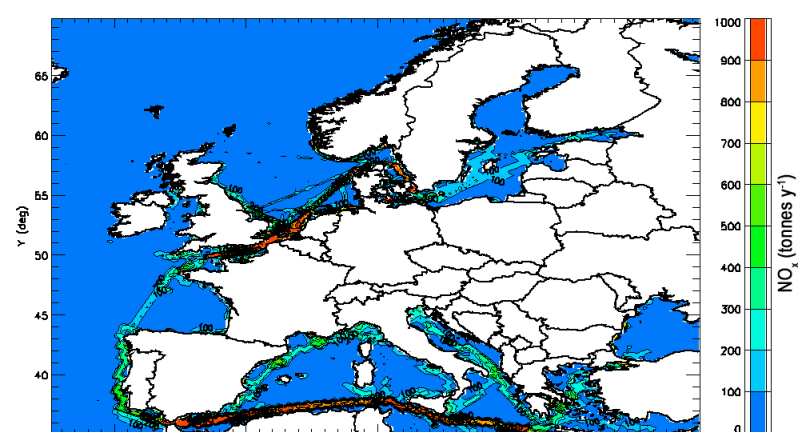

d)

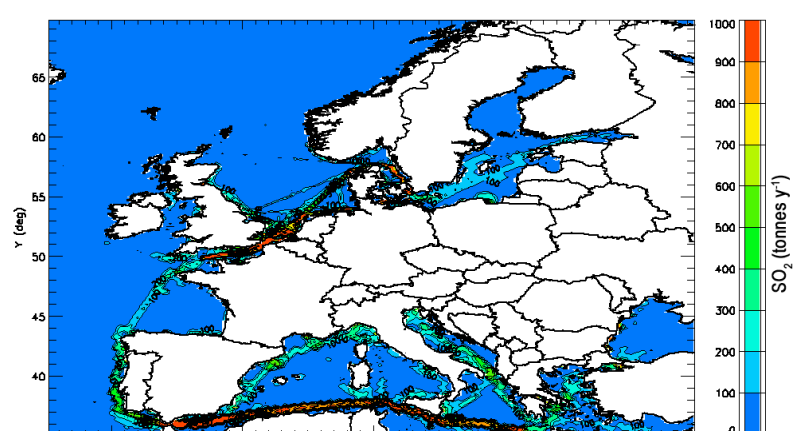

2

3 Fig. S1. Annual ship emissions in 2006 a) $\mathrm{CO}$, b) $\mathrm{NO}_{\mathrm{x}}, \mathrm{c}$ ) $\mathrm{PM}_{2.5}$, d) $\mathrm{SO}_{2}$ (tonnes $\mathrm{y}^{-1}$ ) 

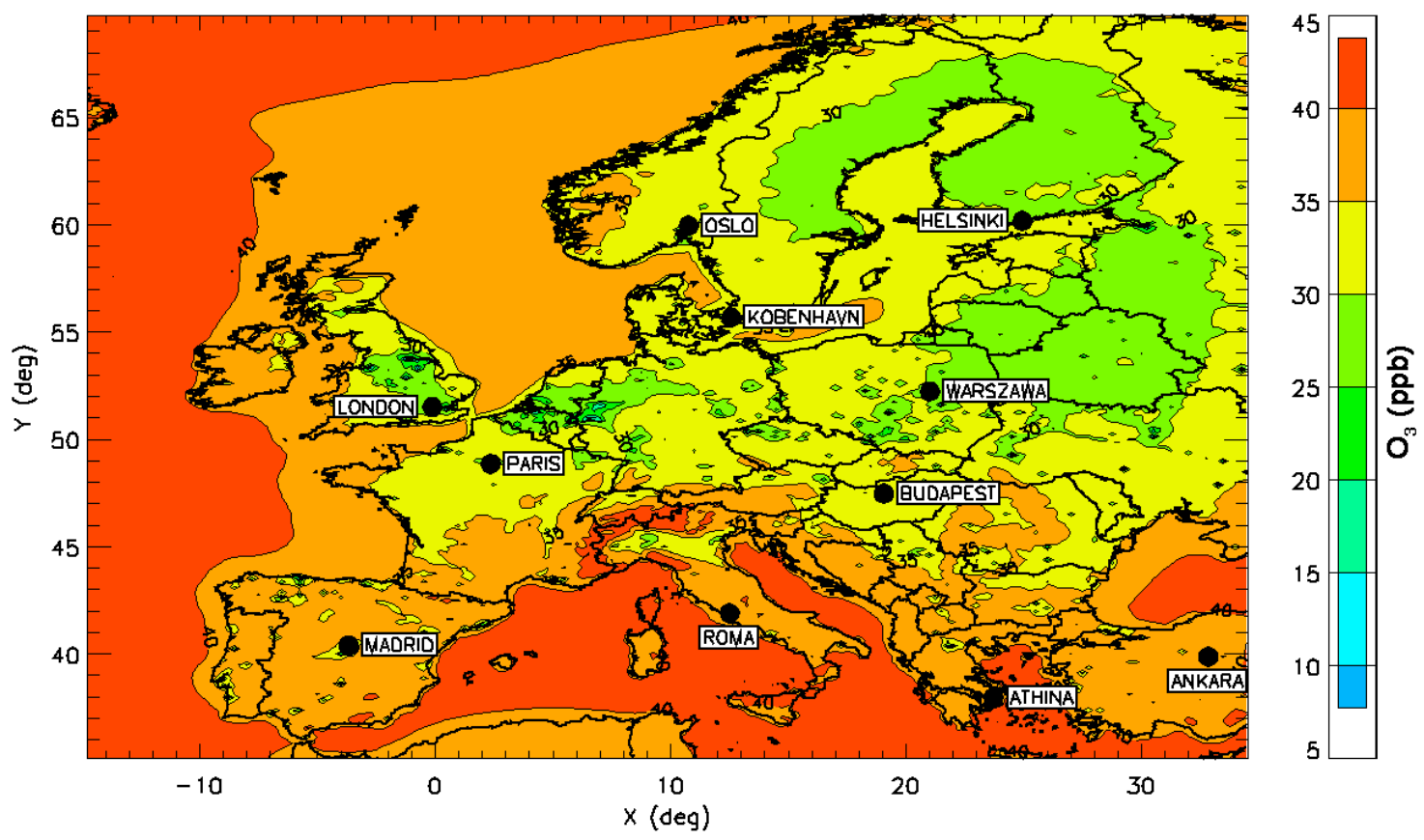

Fig. S2. Annual mean surface $\mathrm{O}_{3}$ mixing ratio (ppb) in 2006 (no ship).
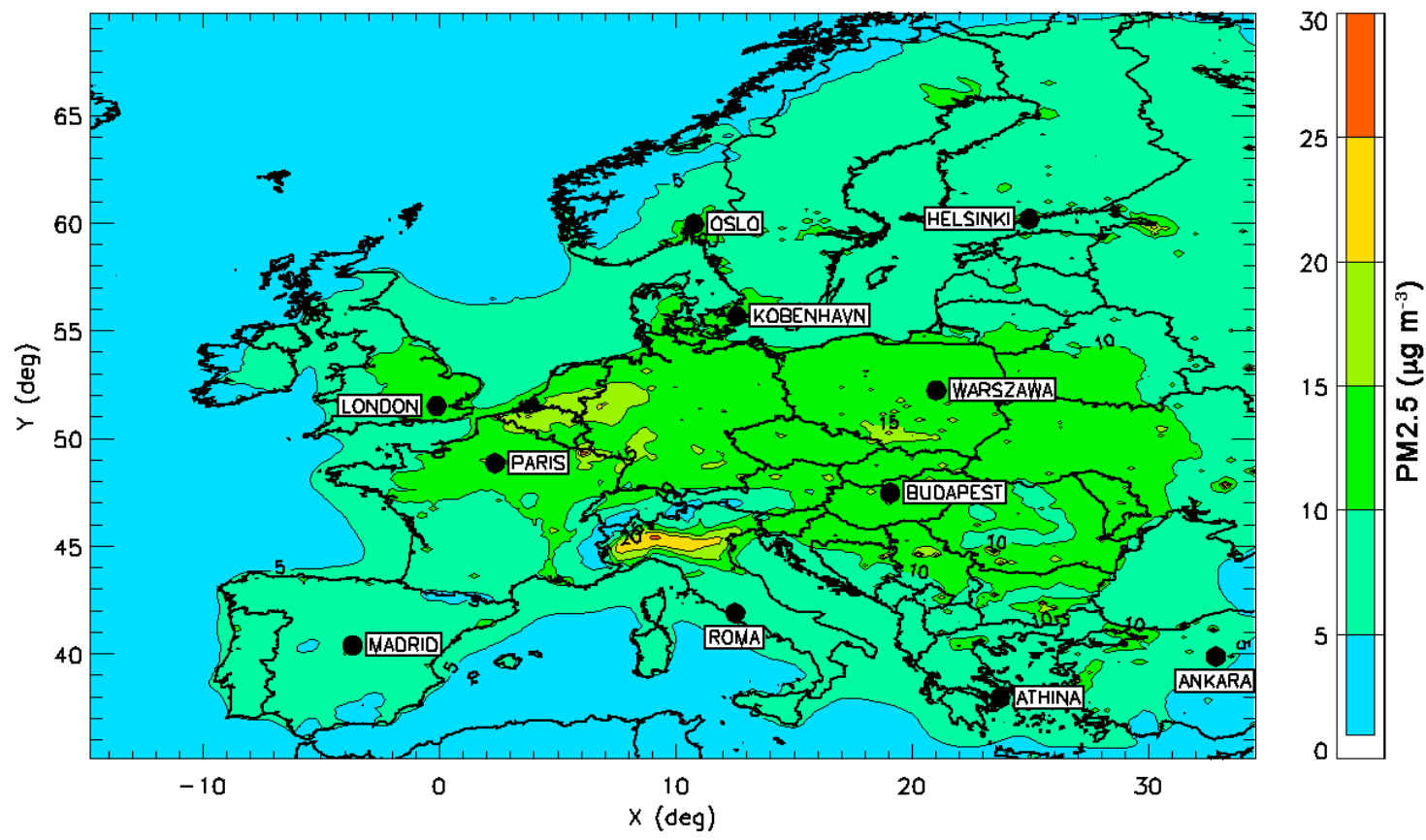

4 Fig. S3. Annual mean $\mathrm{PM}_{2.5}$ concentration $\left(\mu \mathrm{g} \mathrm{m}^{-3}\right)$ in 2006 (no ship). 

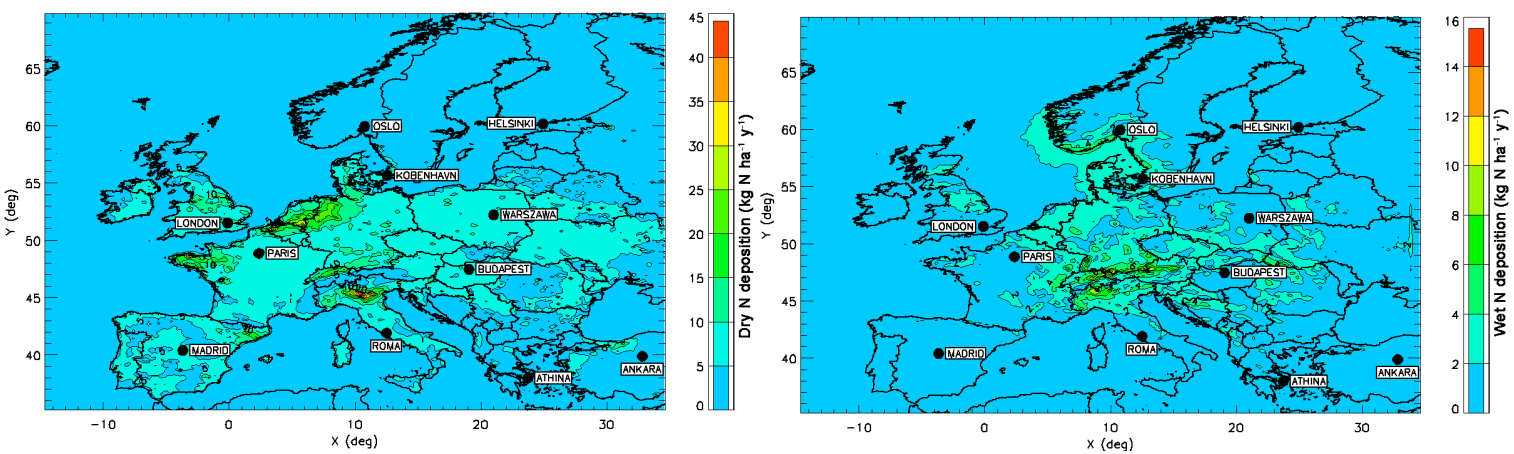

2 Fig. S4. Dry (left) and wet (right) nitrogen deposition ( $\left.\mathrm{kg} \mathrm{N} \mathrm{ha}^{-1} \mathrm{y}^{-1}\right)$ in 2006 (no ship).
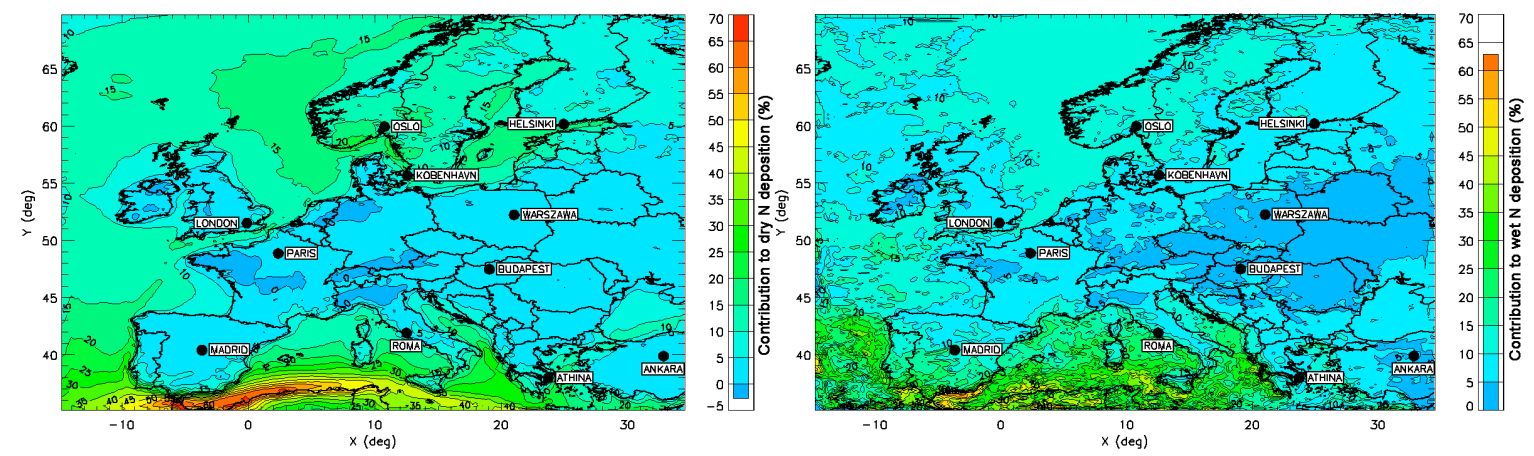

4 Fig. S5. Contribution of ship emissions to dry (left) and wet (right) nitrogen deposition in 2006 (\%) ((base case5 no ship)x100/(base case)).

6

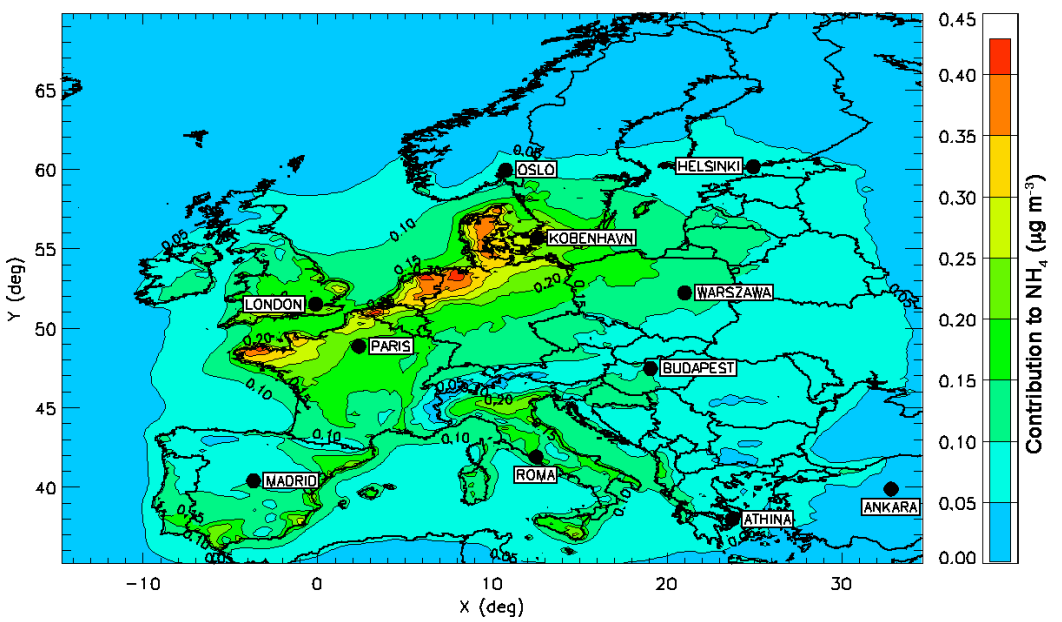

8 Fig. S6. Contribution of ship emissions to $\mathrm{NH}_{4}$ in $2006\left(\mu \mathrm{g} \mathrm{m}{ }^{-3}\right)$ (base case-no ship). 

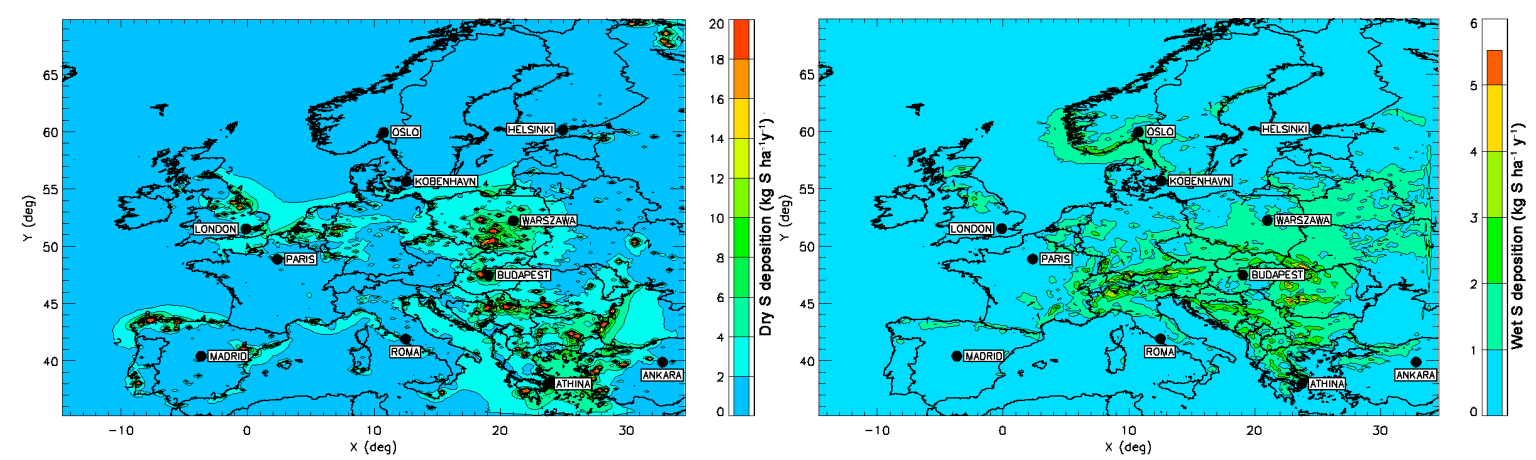

2 Fig. S7. Dry (left) and wet (right) S deposition ( $\left.\mathrm{kg} \mathrm{S} \mathrm{ha}^{-1} \mathrm{y}^{-1}\right)$ in 2006 (no ship). Note that the actual scale for dry 3 deposition (left) is ten times higher.

4
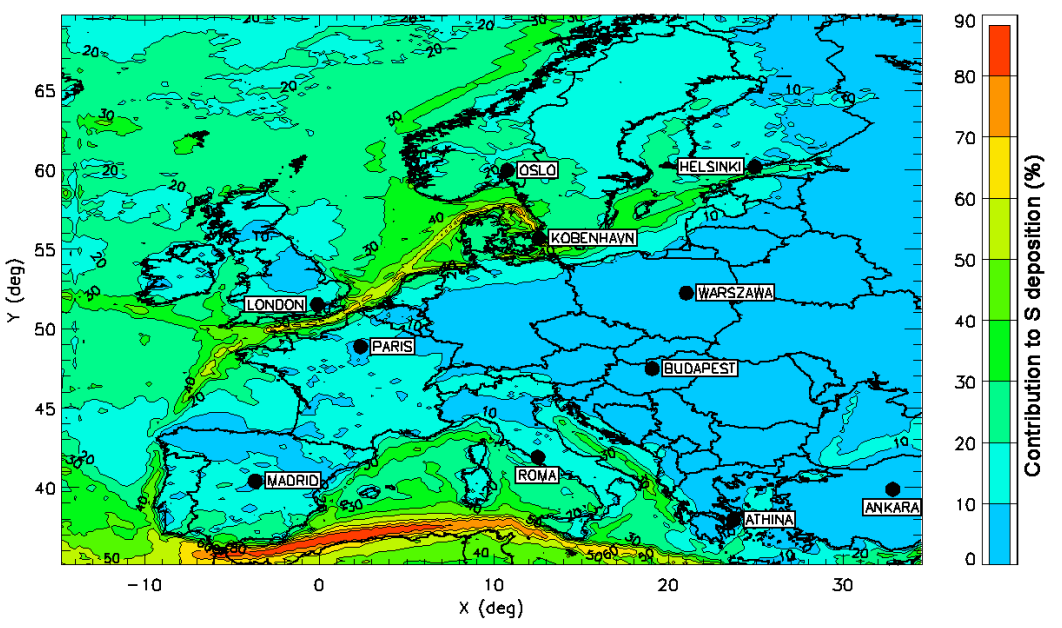

6 Fig. S8. Contribution of ship emissions to S deposition in 2006 (\%) ((base case-no ship)x 100/(base case)). 